\title{
MARTHA NUSSBAUM: HUMANIDADES Y UNIVERSIDAD EN EL SIGLO XXI
}

Rafael González Díaz*

RESUMEN: ¿Qué significado tiene el humanismo en el siglo XXI? ¿Qué papel tienen las humanidades en la universidad? ¿Qué relación tiene la universidad con la sociedad? ¿Cuáles son los presupuestos de una filosofía de la educación relevante para nuestra época? Este artículo busca responder estas preguntas a partir de las reflexiones que Martha Nussbaum ha dedicado a la filosofía educativa. El reto de la educación es el reto del hombre que se bate entre el narcicismo y la interdependencia, entre vergüenza y aceptación de la propia humanidad.

yose

ABSTRACT: What do humanities mean in this century? What role do humanities play in the university? How is the university related to our society? What is the foundation of a meaningful philosophy of education to our times? In this article, we plan to address those questions based on Martha Nussbaum's reflections on educational philosophy. The challenge of education is that of a man who is torn between narcissism and interdependence, shame, and the acceptance of his humanity.

PALABRAS CLAVE: Filosofía educativa, Martha Nussbaum, humanidades, universidad, humanismo. KEY WORDS: Educational philosophy, Martha Nussbaum, humanities, university, humanism.

RECEPCIÓN: 26 de marzo de 2014.

APROBACIÓN: 30 de junio de 2014.

* Departamento Académico de Estudios Generales, ITAM. 
CITAM Derechos Reservados.

La reproducción total o parcial de este artículo se podrá hacer si el ITAM otorga la autorización previamente por escrito. 


\section{MARTHA NUSSBAUM: HUMANIDADES Y UNIVERSIDAD EN EL SIGLO XXI*}

A mi entender, este relato del narcisismo, la indefensión, la impotencia, la vergüenza, la repugnancia y la comprensión constituyen el núcleo de aquello en lo que debe enfocarse la educación para la democracia. ${ }^{1}$

Martha Nussbaum

\section{Preámbulo}

El Anillo del Nibelungo es un drama operístico integrado por un ciclo de cuatro obras en las que Richard Wagner reinterpretó de manera completamente original la riqueza de los mitos germanos y escandinavos. ${ }^{2}$ El proyecto se concibió en 1848 y se concluyó más de veinticinco años después, en 1876. Este largo proceso de gestación incluyó la redacción del libreto y la composición musical. Wagner se inspiró en la teoría de la obra de arte total (Gesamtkunstwerk) ${ }^{3}$

* Este artículo se basa en la ponencia presentada en el V Simposio de la Red Internacional de Estudios Generales (RIDEG), "Interconexión de saberes y formación integral en la Universidad", Puerto Rico, Recinto de Río Piedras, 6 al 9 de noviembre de 2013. Dedico este trabajo a Matías, que me permite entender la frase de Hannah Arendt, "la esencia de la educación es la natalidad, el hecho de que en el mundo hayan nacido seres humanos".

${ }^{1}$ Martha Nussbaum, Sin fines de lucro. ¿Por qué la democracia necesita de las humanidades?, 2010, Buenos Aires, Katz, p. 68.

${ }^{2}$ La obra está compuesta por un prólogo y tres obras: Das Rheingold (El oro del Rin), premier 1869, Munich; Die Walküre, (Las Valquirias) premier, 1870, Munich; Siegfried, (Sigfrido), premier 1876, Bayreuth; y Götterdämmerung (El ocaso de los Dioses), premier, 1876, Bayreuth.

${ }^{3}$ La expresión Gesamtkunstwerk, hace referencia a la obra colectiva en el seno tanto de la polis griega como de la comunidad del futuro. Como señala Dieter Borchmayer, es un concepto 
que pretendía "reunir" las artes, esencialmente, la poesía y la literatura con la música. ${ }^{4}$

En el final de la primera escena del Oro del Rin, prólogo de todo el Anillo del Nibelungo, se presenta una situación con carácter metafórico sobre la tensa relación entre el poder y el amor. ${ }^{5}$ La escena se desarrolla en el Rin, símbolo de la movilidad de la vida y de la naturaleza. En el fondo del río el oro brilla a través de las aguas cristalinas; su belleza reside en el hecho de que no representa otro valor que a sí mismo y en que todavía no ha sido tocado por la codicia de creatura alguna. Las hijas del Rin, las ninfas Woglinde, Wellgunde y Flosshilde, nadan libremente en el río mientras lo custodian. Wellgunde dice: " $\mathrm{La}$ riqueza del mundo podría ser para aquel que con el oro del Rin hiciera un anillo que le otorgara un poder incalculable". ${ }^{6}$ En realidad, están seguras de que nadie querría sacarlo, porque según Woglinde: "sólo a aquel que solemnemente abjure del poder del amor, a aquel que renuncie a los placeres del amor, sólo aquel recibirá la magia para forjar un anillo con el oro"; 7 Wellgunde añade: "entonces, estamos a salvo y no debemos preocuparnos, pues todo lo que vive, quiere amar y nadie renunciará al amor". ${ }^{8}$ Mientras tanto, Alberich, jefe de la raza de los Nibe-

cuasi-político, así como artístico, o tal vez mejor un llamamiento político a la acción, que se contrajo en un lema artístico. El concepto, objeto de múltiples interpretaciones, no tenía la intención de anunciar una unificación de todas las artes. Como imperativo artístico, su implicación fue poco más allá de la unión de la música y la poesía. Así lo comprendió Wagner, que en Über musikalische Kritik identifica explícitamente el Gesamtkunstwerk con esa unión de poesía y música. Cfr. James Garrat, Music, Culture and social reform in the Age of Wagner, 2010, Cambridge (MA), Cambridge University Press, 2010, pp. 166-8; Burton Fisher, Wagner's the Ring of the Nibelung, 2005, Opera Journeys Publishing, Opera Classics Library series, pp. 9-30.

${ }^{4}$ Cfr. Ricardo Miranda, "Obsesiones wagnerianas o apuntes desde la niebla perfumada" en Estudios. Filosofia. Historia. Letras, núm. 107, Invierno 2013, pp. 10-14.

${ }^{5}$ Cfr. Deryck Cooke, I saw the word end: A study of Wagner's Ring, Oxford, Clarendon Paperbacks, 1979, pp. 88-31. Recomiendo la grabación preparada por el musicólogo inglés Deryck Cooke: Der Ring des Nibelungen An Introduction, una célebre introducción que se puede conseguir en castellano bajo el sello DECA, con ejemplos musicales a cargo de Sir Georg Solti dirigiendo a la Filarmónica de Viena; Warren Darcy, Wagner's Das Rheingold, Oxford, Clarendon Press, 1993; J. P. E. Harper-Scott, "Medieval Romance and Wagner's Musical Narrative in the Ring", en $19^{\text {th }}$-Century Music, vol. 32, núm. 3, 2009, pp. 211-34.

${ }^{6}$ Richard Wagner, El oro del Rin (libreto) en: http://www.kareol.es/obras/elorodelrin/ libreto.htm [10 de enero de 2014].

${ }^{7}$ Loc. cit.

${ }^{8}$ Ibidem. 
lungos, observa cautelosamente a las ninfas y se admira de su belleza. Reconoce el intenso deseo que le producen, hasta que se presenta frente a ellas y trata de seducirlas; ellas lo rechazan con sorna, haciéndole ver sus defectos físicos: es enano y deforme. Al ser rechazado, Alberich se propone la posesión del oro y el rechazo del amor. ${ }^{9}$ Esta escena contiene ya todo el conflicto que subyace en el drama entero: la tensa relación entre el poder y el amor, el deseo de posesión que excluye el amor y se convierte en coacción e intención de dominio. Afirma Slavoj Žižek: "en el anillo del Nibelugo, Wagner aborda la cuestión ético-política fundamental del idealismo alemán: cómo es posible unir el amor con la ley”. ${ }^{10}$ Alberich replica: “¿Todavía no tenéis miedo? ¡Pues, vayan a coquetear en la oscuridad, húmedas criaturas! [Alarga el brazo para alcanzar el oro] ;Yo apago vuestra luz, arranco el oro de la roca y forjo el anillo de la venganza! ¡Que las aguas lo escuchen: Yo maldigo al amor!"11

En esta escena cargada de dramatismo se muestra metafóricamente el núcleo de la filosofía educativa de Martha Nussbaum y ejemplifica el dilema que enfrenta todo hombre ante al carácter limitado de su existencia. La indigencia genera sentimientos de vergüenza y repugnancia, que se agravan cuando la educación no facilita la aceptación de la condición humana. El reto de la educación es el reto del hombre que se bate entre el narcicismo y la interdependencia, entre la vergüenza y la aceptación de sí mismo.

\section{Introducción}

La comprensión actual del humanismo está condicionada por los grandes acontecimientos del siglo XX y por la constante acusación de que las humanidades carecen de relevancia intelectual en el presente. Este menosprecio no sólo pone de manifiesto la dificultad de reinterpretar las humanidades, sino que refleja una crisis más profunda que no se puede

${ }^{9}$ La figura de Alberich ha sido estudiada por Adorno, que la entendió como un estereotipo antisemita. V. Theodor Adorno, In Search of Wagner, 2005, New York, Verso, p. 14.

${ }^{10}$ Slavoj Žižek, "Foreword: Why is Wagner Worth Saving" en Adorno, op. cit., p. ix.

${ }^{11}$ Wagner, op. cit. 
desligar de la crisis de la época, o como muchos historiadores la denominan, del fin de una era. ${ }^{12}$

Una de las críticas más agudas realizadas al humanismo es la de Martin Heidegger en su afamado texto Cartas sobre el Humanismo, publicado al final de la Segunda guerra mundial. ${ }^{13}$ El texto era la respuesta a las interrogantes que le hizo llegar Jean Beaufret en 1946. Las preguntas que éste formuló a Heidegger recibieron respuesta explícita: ¿Cómo devolverle un sentido a la palabra "Humanismo”? ¿Cómo salvar el elemento de aventura que hay en toda investigación, sin convertir a la filosofía en una simple aventurera? En este escrito, Heidegger advierte que el humanismo aspira a meditar y cuidarse de que el hombre sea humano en lugar de no-humano, pero el humanismo europeo, a diferencia de lo que se propone, no llega a experimentar la auténtica dignidad del hombre. El humanismo, lo mismo que todos los "ismos", oscurecen y confunden el ser con los entes. Es lo que encontramos a lo largo de la historia del humanismo: que todos los humanismos se han fundado en la metafísica y en el olvido del ser.

Por eso, Heidegger sostiene que ser anti-humanista no implica una defensa de la barbarie o la inhumanidad, como estar en contra de los valores no implica inmoralidad. Afirma que nadie puede defender la prolongación de este modo de ser hombre de la modernidad y que la humanidad europea y americana vive de cara al ser y ocupada exclusivamente en los entes que están a la mano para su dominio. Esa incomprensión del horizonte último del ser por parte de los hombres les impide reconocerse y entenderse a sí mismos y a la naturaleza. ${ }^{14}$

Ese humanismo europeo, dice Heidegger, deja a los individuos sin hogar y sin patria. Sólo un nuevo acercamiento a la verdad y el misterio podría ofrecer una alternativa, pero esta comprensión, según Heidegger, es imposible con las herramientas tradicionales y apremia la construcción

${ }^{12}$ Ana María Carabias Torres, Salamanca y la medida del tiempo, 2012, Salamanca, Ediciones Universidad de Salamanca, pp. 21-59.

${ }^{13}$ Cfr. Martin Heidegger, "Cartas sobre el "humanismo"” en Hitos, 2001, Madrid, Alianza, pp. 259-97.

${ }^{14}$ Cfr. Carla Cordua, Filosofia a destiempo. Seis ensayos sobre Heidegger, 1999, Santiago de Chile, Universidad Nacional Andrés Bello, pp. 67-78. 
de un nuevo sentido para las humanidades. ${ }^{15}$ En palabras de Jean-Luc Nancy, "la inspiración del hombre, no el hombre de un humanismo medido a la escala del hombre dado — ¿y de dónde sacaríamos ese dato?, ¿en qué condición, en qué estatus?-, sino el hombre que supera infinitamente al hombre". ${ }^{16}$

La reflexión de Heidegger tiene continuidad con la de Jacques Derrida, en su luminoso texto Universidad sin condición. Para Derrida "la Universidad reclama y, en teoría, debería garantizársele —además de la llamada libertad académica - una libertad incondicional para cuestionar y aseverar, o yendo aún más lejos, el derecho de decir públicamente todo aquello que sea exigido por la investigación, el conocimiento y el pensamiento concerniente a la verdad". ${ }^{17}$ Este compromiso con la verdad en la Universidad, aunque enigmático y lleno de problemas, puede ser discutido hasta el infinito justo en la universidad y en las carreras que pertenecen a las humanidades. El asunto de la verdad y de su iluminación en la universidad está ligado a la cuestión del hombre, a un determinado concepto de lo que es propio del hombre. Según Derrida, este concepto se reelabora en la Declaración de los Derechos Humanos (1948) y en el concepto jurídico de crimen contra la Humanidad: "E1 concepto de hombre, de lo que es propio del hombre, de derechos humanos, de crímenes contra la humanidad, organiza, como sabemos, la referida mondialisation o mundialización. Esta mundialización querría ser una humanización. Si este concepto de hombre parece indispensable y siempre problemático, bien puede ser [...] discutido y reelaborado, como tal y sin condiciones, sin presuposiciones, solamente dentro del espacio de las nuevas humanidades". ${ }^{18}$

La crisis de las humanidades adquiere sentido dentro de la crisis de la educación, que en realidad es la crisis de una época; sin embargo, toda crisis abre posibilidades, tal y como lo describe Hanna Arendt:

${ }^{15}$ Cfr. Heidegger, op. cit., p. 287.

${ }^{16}$ Jean-Luc Nancy, La verdad de la democracia, 2009, Buenos Aires, Amorrortu, pp. 31-2.

${ }^{17}$ Jacques Derrida, "El futuro de la profesión o la Universidad sin condición (gracias a las 'humanidades', aquello que podría tener lugar mañana)", en Tom Cohen (coord.), Jacques Derrida y las humanidades, 2005, México, Siglo XXI, p. 45.

${ }^{18}$ Ibid, p. 46. 
La oportunidad, nacida de la crisis misma [...] es explorar e inquirir lo que haya quedado a la vista de la esencia del asunto, y la esencia de la educación es la natalidad, el hecho de que en el mundo hayan nacido seres humanos. La desaparición de prejuicios sólo significa que ya no tenemos las respuestas en las que habitualmente nos fundábamos, sin siquiera comprender que en su origen eran respuestas a preguntas. Una crisis nos obliga a volver a plantearnos preguntas y nos exige nuevas o viejas respuestas pero, en cualquier caso, juicios directos. ${ }^{19}$

Las referencias a otros autores podrían multiplicarse, por ejemplo, Giorgio Agamben ${ }^{20}$ o Peter Sloterdijk. ${ }^{21}$

Las aportaciones de Heidegger, Derrida y Hannah Arendt hacen patente que la cuestión sobre las humanidades, la educación y la universidad sigue siendo relevante y que la podemos caracterizar con estas preguntas: ¿Qué significado tiene el humanismo en el siglo XXI? ¿Qué papel tienen las humanidades en la universidad? ¿Qué relación tiene la universidad con la sociedad? ¿Cuáles son los presupuestos de una filosofía de la educación relevante para nuestra época? Este artículo busca respuesta a tales preguntas a partir de las reflexiones sobre filosofía educativa de Martha Nussbaum, o al menos, procura ponderar la pertinencia de sus aportaciones para una respuesta futura a tales preguntas.

En la primera parte, se ofrece al lector una visión panorámica de los grandes temas que han preocupado a Nussbaum; en la segunda, se analiza el núcleo de su filosofía educativa, para juzgar el alcance de su propuesta humanista.

\section{Los principales temas de reflexión de Martha Nussbaum}

En múltiples ocasiones se ha señalado que la filosofía y las disciplinas humanísticas se encuentran alejadas de los problemas inmediatos que aquejan a la sociedad. El mismo Marx, en las Tesis sobre Feuerbach,

${ }^{19}$ Hannah Arendt, "La crisis de la educación", en Entre el pasado y el futuro. Ocho ejercicios sobre la reflexión política, 1996, Barcelona, Península, pp. 270-1.

${ }^{20}$ Cfr. Giorgio Agamben, Lo abierto. El hombre y el animal, 2005, Valencia, Pre-textos.

${ }^{21}$ Cfr. Peter Sloterdijk, Normas para el parque humano, 2006, Madrid, Siruela. 
formuló aquella famosa sentencia: "Los filósofos se han limitado a interpretar el mundo de distintos modos, de lo que se trata es de transformarlo". ${ }^{22}$ La acusación probablemente no sea del todo injustificada, porque efectivamente el quehacer de muchos profesionales de la filosofía y de otras disciplinas humanísticas parece desinteresarse por otros campos del conocimiento. ${ }^{23}$ No obstante, pedirle a la filosofía que se vuelva comentadora de cualquiera de los fenómenos sociales implicaría desnaturalizar sus objetivos. La filosofía y las humanidades tienen sus propios objetivos y métodos, pero eso no las exime de un diálogo continuo con otros campos del conocimiento, las matemáticas, las ciencias sociales y la economía, entre otros. ${ }^{24}$ Un ejemplo de lo provechoso que puede resultar esta relación es la obra de la galardonada en el año 2012 con el premio Príncipe de Asturias en Ciencias Sociales. ${ }^{25}$

Su obra es extensa tanto individual como colectivamente; la mayor parte está traducida al español y comprende una variada serie de temas sobre los que se asientan sus reflexiones. El objetivo de este trabajo gira en torno a la educación, las humanidades y la universidad, por lo que solo se presentará una visión de conjunto del trabajo de esta filósofa, a la que añadiremos una extensa investigación bibliográfica para facilitar al lector futuros acercamientos. Anticipamos que la obra de Nussbaum se agrupa en torno de ciertos ejes: a) la investigación de los clásicos griegos, de Aristóteles en particular; b) la relación entre la filosofía y las ciencias económicas; c) la preocupación por la exclusión en la esfera económica, social, política y religiosa; d) la defensa de la educación liberal; y, e) la reivindicación de las humanidades y los sentimientos morales.

${ }^{22}$ Carlos Marx, "Tesis sobre Feuerbach" en C. Marx y F. Engels, La ideología alemana, 1959, Montevideo, EPU, trad. de W. Roces, p. 653.

${ }^{23}$ Cfr. Edgar Morin y Anne Kern, Tierra patria, 2006, Buenos Aires, Nueva Visión, pp. 57; 66-7.

${ }^{24}$ Cfr. G. W. Friedrich Hegel, Líneas fundamentales de la filosofia del derecho, 2010, Madrid, Gredos, pp. 14-25.

${ }^{25}$ Ver http://www.fpa.es/es/premios-principe-de-asturias/premiados/2012-martha-cnussbaum.html?especifica $=0$ [10 de enero de 2014]. 
En primer lugar, destaca el estudio de los clásicos griegos y de la interpretación de la obra de Aristóteles; ${ }^{26}$ la tesis con la que obtuvo el grado de doctora, tiene como tema el movimiento de los animales en Aristóteles. ${ }^{27}$ Las investigaciones sobre la filosofía política y sobre el concepto de justicia distributiva en el Estagirita le han permitido construir con el tiempo una abundante meditación y mantener debates continuos con pensadores de otras escuelas. ${ }^{28}$ En segundo lugar, destacan sus esfuerzos por relacionar la filosofía y las ciencias económicas; es significativa su colaboración con el premio Nobel de economía, Amartya Sen y sus esfuerzos conjuntos en el campo de la ciencia económica para redimensionar el concepto de desarrollo humano. ${ }^{29}$ Durante la década de 1980, se dedicaron a promover la noción de capacidades y cuestionaron los conceptos tradicionales de desarrollo; en sus trabajos promovieron el "enfoque de las capacidades" como elemento constitutivo del desarrollo y vincularon su ausencia con la pobreza. ${ }^{30}$ Desde

${ }^{26} \mathrm{Cfr}$. Martha Nussbaum, La fragilidad del bien: fortuna y ética en la tragedia y la filosofía griega, 1995, Madrid, Visor; La terapia del deseo: teoría y práctica de la ética helenística, 2003, Barcelona, Paidós. En otros de sus textos hay referencias frecuentes al pensamiento clásico, vg., Sin fines de lucro. ¿Por qué la democracia necesita de las humanidades?, 2010, Buenos Aires, Katz; El cultivo de la humanidad, 2005, Barcelona, Paidós; El ocultamiento de la humano. Repugnancia, vergüenza y ley, 2006, Buenos Aires, Katz; Libertad de conciencia: Contra los fanatismos, 2009, Barcelona, Tusquets; Paisajes del pensamiento, 2008, Barcelona, Paidós; Justicia poética, 1997, Barcelona, Andrés Bello; El conocimiento del amor: ensayos sobre filosofia y literatura, 2005, Madrid, Antonio Machado Libros; Libertad de conciencia: el ataque a la igualdad de respeto, 2011, Buenos Aires, Katz; Las fronteras de la justicia: consideraciones sobre la exclusión, 2007, Barcelona, Paidós.

${ }^{27}$ Martha Nussbaum, Aristotle's De motu animalum, 1985, Princeton, Princeton University Press.

${ }^{28}$ Martha Nussbaum, "Virtudes no relativas: un enfoque aristotélico" en Amartya Sen y Martha Nussbaum, (comps.), La calidad de vida, 1993, México, FCE; "Human functioning and social Justice: In defense of Aristotelian Essentialism" en Political Theory, vol. 20, núm. 2, Mayo 1992, pp. 202-46; Nature, function, and capability: Aristotle on Political Distribution, 1987, World Institute for Development Economics Research of the United Nations University (publicado también por Oxford Studies in Ancient Philosophy, Supplementary Volume, 1988, pp. 145-85); "Aristotle, Politics, and human capabilities: A response to Antony, Arenson, Charlesworth, and Mulgan”, en Ethics, vol. 111, núm. 1, Octubre 2000, pp. 102-40; “Aristotelian Social Democracy” en R. B. Douglas, G. M. Mara y H. S. Richardson, (eds.), Liberalism and the Good, 1990, New York, Routledge, pp. 203-52.

${ }^{29}$ Véase Amartya Sen, Poverty and Famines. An Essay on Entitlement and Deprivation, 1983, Oxford, OuP; La idea de justicia, 2010, Madrid, Taurus; Sobre Ética y economía, 1989, Madrid, Alianza.

${ }^{30}$ Cfr. Séverine Deneulin, "Recovering Nussbaum's Aristotelian Roots" en Revista Cultura Económica, año XXIX, núm. 81-82, diciembre 2011, pp. 31-7. 
su perspectiva, el modelo de desarrollo centrado en el aumento de la renta es insuficiente porque sólo permite un acercamiento cuantitativo a los fenómenos económicos, ignorando la dimensión cualitativa del desarrollo. El problema está en identificar el progreso de una nación exclusivamente con el incremento del producto interno bruto. Afirma Nussbaum:

Lo que nosotros hemos estado defendiendo, entonces, es que la medida correcta del desarrollo se focaliza en las personas, es sensible a la distribución y es plural; refleja el hecho de que la gente no lucha por la renta nacional, lucha por una vida con sentido para ellos mismos. Al desarrollar una lista de las capacidades humanas centrales, que afirmo son los requisitos mínimos de una vida conforme a la dignidad humana, he tratado de dar cuerpo a estas ideas y de sugerir algunas metas concretas para todas las naciones. ${ }^{31}$

Según este modelo, el único objetivo de toda nación debería ser el crecimiento económico, sin importar la distribución de la riqueza ni las condiciones sociales que posibilitan la concordia social; parece que los aspectos no vinculados con el crecimiento económico carecen de importancia. Esos trabajos influyeron de manera decisiva en las formulaciones del Programa de Naciones Unidas para el Desarrollo (PNUD) y el diseño de los Indicadores de Desarrollo Humano (IDH), fruto de la estrecha colaboración de Mahbub ul-Haq y Amartya Sen, considerados creadores de los Informes sobre desarrollo humano. Su enfoque ha guiado por más de veinte años el trabajo de estos organismos. ${ }^{32}$ En el discurso de recepción del premio Príncipe de Asturias, Martha Nussbaum señalaba:

Creo que este trabajo es, sin duda, una contribución a las Ciencias Sociales y a la economía del desarrollo en particular. Con frecuencia la

${ }^{31}$ Martha Nussbaum, Discurso recepción Premio Príncipe de Asturias 2012, op. cit. Véase también el Programa de Naciones Unidas para el Desarrollo, http://hdr.undp.org/en/humandev [15 de enero de 2014].

${ }^{32} \mathrm{Cfr}$. Ian Gough, "El enfoque de las capacidades de M. Nussbaum: un análisis comparado con nuestra teoría de las necesidades humanas" en Papeles de relaciones ecosociales y cambio global, núm. 100, 2007/08, pp. 177-202. 
economía se centra de forma restringida en el crecimiento; pero en el fondo se trata de una disciplina normativa enfocada en las personas y precisa lo que tenía en sus inicios, el input de la filosofía, para articular los objetivos de una buena sociedad que sea sensible a las personas. La importancia que tiene la filosofía para la economía sugiere algo más, lo que constituye otro tema de mi trabajo: necesitamos una educación bien fundada en las humanidades para realizar el potencial de las sociedades que luchan por la justicia. ${ }^{33}$

Un tercer aspecto que posibilita la comprensión de la obra de Nussbaum es su preocupación constante por la exclusión y por la defensa de la tolerancia. La reivindicación de las personas en situación de marginalidad se extiende a las esferas política, económica, religiosa y social. En este sentido, dedica una parte importante de sus escritos a la tolerancia religiosa, la equidad de género, los derechos de las niñas y las mujeres, la justicia social y la defensa de la democracia y la ciudadanía. $^{34}$

Su trabajo también se ha orientado en torno a un tema al que la filosofía no dedica mucha atención y que es objeto de múltiples debates: las emociones. ${ }^{35}$ Acusada en algunas ocasiones de caer en explicaciones biologicistas o psicologizantes, se ha dedicado a elaborar una compleja teoría de las emociones que ha ido desarrollando a lo largo de los años en libros como Justicia Poética, El conocimiento del Amor, La fragilidad del bien, Paisajes del pensamiento y el más reciente, Political Emotions: Why love matters for Justice. ${ }^{36}$ Incluso, para algunos inves-

${ }^{33}$ Nussbaum, Discurso..., op. cit.

${ }^{34}$ Nussbaum, Libertad de conciencia..., op. cit.; Las mujeres y el desarrollo humano. El enfoque de las capacidades, 2012, Barcelona, Herder; Crear capacidades: propuesta para el desarrollo humano, 2012, Barcelona, Paidós; La nueva intolerancia religiosa. Cómo superar la política del miedo en una época de inseguridad, 2013, Barcelona, Paidós; Las fronteras de la justicia, op. cit.; India, 2009, Barcelona, Paidós; Justicia poética, op. cit.; Libertad de conciencia..., op. cit.; El ocultamiento de la humano..., op. cit.

${ }^{35}$ Helena Modzelewki, La educabilidad de las emociones y su impacto para el desarrollo de un ethos democrático. La teoría de las emociones de Martha Nussbaum y su expansión a través del concepto de autoreflexión, Tesis de doctorado, Departamento de Filosofía del Derecho, Moral y Política, Universidad de Valencia, 2012.

${ }^{36}$ Cfr., Martha Nussbaum, Political Emotions. Why love matters for justice, 2013, Cambridge (MA), Harvard University Press. Las primeras impresiones y los cuestionamientos no se han 
tigadores su propuesta está estrechamente vinculada con la filosofía de David Hume. ${ }^{37}$

En estos trabajos se analiza la relación de las emociones con el florecimiento de la persona y su importancia en la vida ética. Ligado a todo esto, la defensa apasionada por la literatura y las artes como vehículo y medio para humanizar y “desespecializar” a los futuros abogados y economistas. No debemos olvidar que Nussbaum ocupa la cátedra de Derecho y Ética en el Departamento de Filosofía de la Facultad de Derecho y la Divinity School de la Universidad de Chicago. Nussbaum ha insistido reiteradamente en que las obras de arte pueden incitar determinadas emociones que resultan muy útiles para la ética. En el discurso de recepción ya citado, manifiesta:

Las humanidades nos proporcionan no sólo conocimientos sobre nosotros mismos y sobre los demás, sino que nos hacen reflexionar sobre la vulnerabilidad humana y la aspiración de todo individuo a la justicia, y nos evitarían utilizar pasivamente un concepto técnico, no relacionado con la persona, para definir cuáles son los objetivos de una determinada sociedad. No me parece demasiado atrevido afirmar que el florecimiento humano requiere el florecimiento de las disciplinas de humanidades. ${ }^{38}$

En síntesis, la obra de Nussbaum es relevante, extensa y no está exenta de polémica; se ha convertido incluso en tema de estudio especializado en muchas universidades del mundo.

hecho esperar; véase en particular Malcom Thorndike, "Intellectual motion-sickness, en Prospect Magazine, $1^{\circ}$ de octubre de 2013 [http://www.prospectmagazine.co.uk/art-books/marthanussbaum-political-emotions-why-love-matters-for-justice-review/\#.U7HphpR5OVM], y Stanley Fisch, "Love and politics", The New York Times, 4 de octubre del 2013 [http://www. nytimes.com/2013/10/15/opinion/fish-love-and-politics.html?pagewanted=all\&_r=0 ]. También en México se ha escrito alguna crítica, aunque lamentablemente demasiado parecida a la de Thorndike, v. Jesús Silva Herzog M., "De emociones y premios", Reforma, 4 de noviembre, 2013 [http://criteriohidalgo.com/notas.asp?id=201436].

${ }^{37}$ Ryan Patrick Hanley, "David Hume and the 'Politics of Humanity", en Political Theory, vol. 39, núm. 2, Abril 2011, pp. 205-33.

${ }^{38}$ Nussbaum, Discurso..., op. cit. 


\section{Características generales de la filosofía educativa de Martha Nussbaum}

La filosofía de la educación de Nussbaum se nutre de la reflexión de pensadores como Rousseau, Friedrich Frobel, Johann Pestalozzi, Bronson Alcott, María Montessori y Tagore ${ }^{39}$ y se desarrolla de manera explícita en dos de sus obras: El cultivo de la Humanidad. Una defensa clásica de la reforma de la educación liberal y Sin Fines de Lucro. ¿Por qué la democracia necesita de las humanidades? ${ }^{40}$ En ellas, Nussbaum manifiesta los rasgos de su filosofía de la educación y, de modo implícito, su noción de lo humano y de su cultivo en la universidad. Los agruparé por temas para analizarlos y poder juzgarlos más adelante: a) la pedagogía socrática; b) la crítica de sí mismo y de la propia tradición; c) el pluralismo cultural y el discernimiento moral; d) la educación para la democracia; e) el ocio y la otredad en la educación; y, f) la comprensión de la propia finitud, la compasión y la solidaridad. Analizar y criticar cada uno de ellos rebasaría la extensión debida, por lo que trataré de señalar lo más significativo.

La importancia del diálogo en la educación resulta evidente; sin embargo, se vuelve consejo manido de pedagogos o de especialistas en educación; para Nussbaum, la educación es diálogo pero al modo de la pedagogía socrática, un intercambio que posibilita el nacimiento y el desarrollo de la subjetividad. Una vez más, la figura de Sócrates emerge como símbolo del urgente parto de las almas. ${ }^{41}$ Carlos de la Isla, humanista y educador mexicano, lo describe de este modo:

Pienso que la gran labor del maestro es acompañar al alumno en el proceso de gestación y parto (Sócrates) de sus ideas, que son el móvil asombroso de su existencia. Colaborar con el alumno para que pueda vivir su vida

${ }^{39} \mathrm{Cfr}$. Martha Nussbaum, "Tagore, Dewey, and the imminent Demise of Liberal Education" en Harvey Siegel (comp.), The Oxford Handbook of Philosophy of Education, 2009, Oxford, OUP.

${ }^{40}$ Véase el interesante volumen de Guillermo Hoyos Vázquez (ed.), Filosofía de la educación, 2008, Madrid, Trota, p. 20.

${ }^{41}$ Cfr. José Vasconcelos, Pedagogía estructurativa, 2002, México, Senado de la República, p. 24. 
en este mundo, donde los grupos de poder se han propuesto manejar a las personas como marionetas, imponiendo ideas e ideales, valores y valoraciones, modas, modos y modales. Por eso, he dicho que genio es el que logra ser él mismo a pesar de todos los condicionamientos del medio. ${ }^{42}$

En la obra de Nussbaum son recurrentes los ejemplos sobre los beneficios que para los estudiantes implica el acercamiento, por medio de la lectura y la discusión, a las grandes obras de la literatura y la filosofía. $\mathrm{Su}$ valor no reside en la formación libresca que se pudiera presentar, sino en los frutos que produce el cuestionamiento y el diálogo. ${ }^{43}$

La naturaleza del acto educativo como posibilidad para el surgimiento de la subjetividad requiere, según lo propone Nussbaum, del examen crítico de uno mismo y de la propia tradición. Resulta imperioso que la educación permita la superación de los límites de la conciencia de clase, la nacionalidad, el género y favorezca el desarrollo de la autonomía personal y la participación responsable en la sociedad. La denomina pedagogía socrática o mayéutica; se representa como una condición indispensable para que la universidad siga siendo el espacio privilegiado para la crítica y la reflexión en una sociedad. ${ }^{44}$ Estos planteamientos coinciden también, en mayor o menor medida, además de con las propuestas de filósofos y humanistas ya mencionados, con la de algunos educadores latinoamericanos, como José Vasconcelos, Pedro Henríquez Ureña, Andrés Bello, Eugenio María de Hostos, Domingo Faustino Sarmiento, Rafael Heliodoro Valle, José Trinidad Reyes, Agustín Nieto Caballero y José Antonio Encinas Franco, entre otros.

Desde la perspectiva de Nussbaum, la educación liberal se ha comprometido históricamente con este proyecto educativo, pero el sentido

${ }^{42}$ Rafael González Díaz, "Entrevista a Carlos de la Isla: el rostro humano en la educación contemporánea”, en Estudios. Filosofía. Historia. Letras, núm. 101, Verano 2012, pp. 118-9.

${ }^{43}$ Cfr. José Barba, "La evaluación del diálogo. Su espíritu. Su método", en Estudios. Filosofia. Historia. Letras, núm. 79, Invierno 2006, pp. 106-121; Carlos de la Isla, "Reflexiones sobre el método dialógico" en Estudios. Filosofía. Historia. Letras, núm. 70, Otoño 2004, pp. 7-19. Recomiendo Jens Peter Brune, Horst Gronke y Dieter Krohn (eds.), The challenge of Dialogue. Socratic Dialogue and others from of Dialogue in different political systems and cultures, 2010, Berlin, Lit Verlag.

${ }^{44} \mathrm{Cfr}$. Peter Euben, Corrupting Youth. Political education, democratic culture and political theory, Princeton, Princeton University Press, 1997, pp. 32-63. 
de la misma no se encuentra libre de debates. ${ }^{45}$ Su obra es un esfuerzo por reinterpretar el sentido y alcance de los atributos de la educación liberal. Sin desacreditar el valor que tiene el estudio de los clásicos, propone que esta educación no ignore las preocupaciones que se originan en una sociedad plural en la que convergen distintas culturas; por otro lado, se declara defensora de la educación liberal frente a la educación centrada en la renta y el crecimiento económico. Su reflexión guarda afinidades con la de Derek Bok, en la que advierte sobre los riesgos que estas prácticas pueden tener para los valores académicos. ${ }^{46}$ Para Nussbaum, el modelo educativo imperante concibe como obligación convertir a la educación en la herramienta exclusiva para el aumento de la renta nacional, sin tomar en cuenta las evidencias de que el crecimiento económico no necesariamente implica una mejora en la calidad de vida de las personas y de la sociedad. Lo más grave, según ella, está en que su descuido representa un peligro real para la sociedad, puesto que no se percatan de que sin una sólida formación humanística, las democracias se debilitan y el crecimiento económico es insostenible, salvo mediante la aplicación de mecanismos violentos y autoritarios. ${ }^{47}$

Estas presiones sobre la formación humanista provocan una disyuntiva en la organización curricular de las instituciones de educación su84 perior que, en aras de la eficiencia, han reducido, y en algunos casos, eliminado la formación humanística. ${ }^{48}$

De acuerdo con Nussbaum, la educación liberal ha cultivado durante siglos las humanidades sin perjuicio de la ciencia y la tecnología; el verdadero cultivo de las humanidades favorece el examen de uno mismo, la capacidad de diálogo, la imaginación, la crítica de la propia

${ }^{45}$ Cfr. Rodolfo Vázquez, "Un enfoque liberal de la educación" en Revista Estudios. Filosofia. Historia. Letras, núm. 30, otoño 1992, pp. 81-92; Elizabeth Kiss y Peter Euben (eds.), Debating moral education. Rethinking the role of Modern University, 2010, Durham, Duke University Press, pp. 38-46; Alex Beam, A great idea all the time. The Rise fall and curious Afterlife of the Great Books, 2008, New York, Public Affairs, pp. 1-19.

${ }^{46}$ Derek Bok, Universidades a la venta. La comercialización de la educación superior, 2010, Valencia, Universitat de Valencia.

${ }^{47}$ Cfr. Nussbaum, Sin fines de lucro.., op. cit., p. 199; El cultivo de la humanidad, op. cit.

${ }^{48}$ Cfr. Carla Cordua, "La crisis de las humanidades" en Revista de Filosofia, Universidad de Chile, vol. 68, 2012, pp. 7-9; Rafael González Díaz, "Evaluación del enfoque educativo imperante basado en el desarrollo de competencias a la luz de la educación mayéutica", en Estudios. Filosofía. Historia. Letras, núm. 97, Verano 2011, pp. 73-102. 
tradición cultural y la comprensión mutua a pesar de las diferencias. Según nuestra filósofa, actualmente estamos en medio de una crisis silenciosa de enorme gravedad mundial, y no precisamente en la esfera económica, sino en materia educativa; con el tiempo puede resultar más perjudicial que la primera, ya que podría afectar de manera decisiva la salud de las democracias. El cambio se produce en el núcleo de lo que se enseña a los jóvenes dentro de las sociedades democráticas; sin embargo, en la mayoría de estos casos, tales transformaciones no se sometieron a un análisis detallado:

Sedientos de dinero, los estados nacionales y sus sistemas de educación están descartando sin advertirlo ciertas aptitudes que son necesarias para mantener vida la democracia. Si esta tendencia se prolonga, las naciones de todo el mundo, en breve, producirán generaciones enteras de máquinas utilitarias, en lugar de ciudadanos cabales con la capacidad de pensar por sí mismos, poseer una mirada crítica sobre las tradiciones y comprender la importancia de los logros y sufrimientos ajenos. ${ }^{49}$

Entre los cambios más drásticos está la erradicación de las asignaturas y carreras relacionadas con las humanidades en muchas universidades e instituciones de educación media y superior: se les considera un ornamento dispendioso porque no parece brindar una utilidad inmediata para ser competitivos en el mercado global. La crisis ya había sido anunciada por otros especialistas, como Engell James y Anthony Dangerfield en sus trabajos sobre el modelo de mercado en la universidad y el papel de las humanidades en la era del dinero. Las investigaciones sobre la crisis futura de la educación en Estados Unidos se multiplicaron en la década de $1980 .^{50}$

Nussbaum afirma que incluso el aspecto humanístico de muchas ciencias, es decir, el relacionado con la imaginación, la creatividad y

${ }^{49}$ Nussbaum, Sin fines de lucro..., op. cit., p. 20.

${ }^{50}$ Para un sumario recorrido histórico y las características de la crisis de la educación americana, recomiendo el texto de Derek Bok, Our underachieving colleges. A Candid Look at How Much Students Learn and Why They Should Be Learning More, 2006, Princeton, Princeton University Press; resulta conveniente consultar también Richard Levin, "El mejor de la clase. El ascenso de las universidades asiáticas”, en Foreing Affairs Latinoamerica, vol. 10, núm. 2010, pp. 88-9. 
el rigor del pensamiento crítico también está perdiendo terreno en la medida en que los países se centran en la rentabilidad a corto plazo y en la formación de capacidades utilitarias y aptas para generar renta. ${ }^{51}$ Distintos proyectos e informes coinciden en que actualmente predomina una concepción que gira en torno a la rentabilidad; este nuevo paradigma de la educación y su aparato conceptual remiten de manera inmediata a la esfera económica e industrial. Se insiste en la necesidad casi obsesiva de establecer mediciones que estandaricen la capacidad de los estudiantes para "saber hacer en un contexto"; sin duda, esta noción respondía de manera puntual a la exigencia de adecuación de las acciones educativas con las de la industria. ${ }^{52}$

A pesar de las resistencias iniciales, dicha orientación se ha ido imponiendo en la mayor parte de las reformas educativas en Europa y Latinoamérica. Nussbaum reconoce esta situación y advierte los riesgos que implican tales políticas para el futuro desarrollo de la persona, la democracia y la misma economía. Como lo había dicho Robert Maynard Hutchins en su memorable texto La enseñanza superior en Estados Unidos (1936), el primero de los riesgos "es muy vulgar, es el amor al dinero. Es triste, pero cierto, que cuando una institución se determina hacer algo con el fin de conseguir dinero debe perder su alma, y con frecuencia no recibe el dinero". 53

En muchos países, incluidos los Estados Unidos, esta política ha tenido que enfrentar el rechazo de un sector importante de la población, porque existe una larga tradición universitaria basada en las disciplinas humanísticas. Una característica de esa cultura educativa es la participación activa de los alumnos en la investigación de los temas, la formulación de preguntas y un espíritu crítico en la indagación. Eso explica, en parte, el motivo por el cual no ha existido nunca un modelo de educación centrado exclusivamente en el crecimiento económico.

${ }^{51}$ Cfr. James Engell y Anthony Dangerfield, "The Market-Model University: Humanities in the Age of Money" en Harvard Magazine, núm. 111, 1998, pp. 45-88; Saving Higher education in the Age of Money, 2005, Charlottesville (VA), University of Virginia Press, pp. 79-124. Recomiendo el capítulo cuarto y quinto, dedicados a las humanidades, el modelo de mercado y la destrucción de la lectura.

${ }^{52}$ Cfr. González Díaz, "Evaluación del enfoque educativo..., op. cit., p. 75.

${ }^{53}$ Robert Hutchins, The higher learning in America, 2009, Chicago, Transaction Publishers, p. 5 . 
Es notoria también la resistencia del sistema educativo para adaptarse a dicho modelo; los alumnos, al ingresar a la universidad para estudiar una carrera determinada, están obligados a cursar una variedad de materias durante los primeros años de su formación, entre las que predominan las humanidades; en palabras de Nussbaum: "Nadie queda encasillado antes de tiempo en una educación puramente científica o técnica, pero jóvenes con una inclinación marcada por las humanidades tampoco pierden el contacto con la ciencia antes de tiempo". ${ }^{54}$ Aunque este modelo permanece anclado en la tradición americana, se encuentra sometido a una fuerte presión, especialmente a raíz de la crisis económica de 2008.

La educación liberal se relaciona con una larga tradición occidental que nace desde la época clásica, pasa por el nacimiento de la universidad y llega a su moderna configuración. Como lo señala Carlos de la Isla, refiriéndose a lo sostenido por Raymond Aron, las universidades europeas son instituciones a las que la sociedad moderna de tipo industrial impone e impondrá profundas transformaciones. ${ }^{55}$

Las tensiones a las que se ve sujeta la universidad se han hecho más agudas a partir de la modernidad. La concepción del educador como operario necesita una reflexión sobre sus vínculos con el currículo, las representaciones sociales del educando y el modo en que se organizaron las instituciones encargadas de brindar educación. ${ }^{56}$ La idea de que todo educador es agente de cultura pone de manifiesto la importancia que juegan los complejos dispositivos que prescriben dónde, cómo y qué se debe enseñar. ${ }^{57}$ En Occidente, dicha rigurosa organización de los saberes coincide con una nueva manera de entender la racionalidad que desde el inicio de la modernidad fue consolidándose. Este tipo de racionalidad técnico-instrumental no tiene tanto interés en la determinación de los fines, como en la eficacia y la regulación de los medios para alcanzar el progreso material y moral de la sociedad. Es decir, se funda en la convicción de que la razón es, antes que nada, el instrumen-

${ }^{54}$ Nussbaum, Sin fines de lucro..., op. cit., p. 39.

${ }^{55}$ Carlos de la Isla, "Reflexiones en plural sobre el camino hacia lo humano en la educación superior" en Revista del Instituto Tecnológico Autónomo de México, núm. 1, Verano 1973, p. 4.

${ }^{56}$ Michael Apple, Ideología y currículo, 2008, Madrid, Akal.

${ }^{57}$ Michel Foucault, Vigilar y castigar. Nacimiento de la prisión, 2009, México, Siglo XXI. 
to que puede y debe hacer eficientes las acciones en cualquier dimensión de la vida humana. ${ }^{58}$ En el ámbito educativo, tal racionalidad implica que la selección de contenidos debe tecnificarse; para ello, se invoca un conjunto de disciplinas y evidencias científicas que se admiten como legítimas y objetivas para ordenar el discurso educativo e incluso la sociedad. Estos contenidos, sancionados por tal racionalidad, se perciben como un valor abstracto frente a las vicisitudes de la historia concreta de las personas. La consecuencia directa es que tiende a estimarse como insustancial lo que el educador pueda decir sobre los contenidos que ha de enseñar y, lo que parece todavía más grave, sobre la manera en que debe ser enseñado. El entorno concreto en que se desenvuelve el educador es ignorado para subordinarse al canon de conocimientos abstractos que deben alcanzarse.

Sin duda, la noción de currículo es antigua y se fue fraguando de manera simultánea con los procesos de escolarización que se desarrollaron en los siglos XVI y XVII. El término latino curriculum, que se refería a la pista circular de atletismo, se encuentra registrado por primera vez, según el Oxford English Dictionary, de 1633, en la Universidad de Glasgow, y se inserta en el marco de la Reforma protestante y la expansión del calvinismo. ${ }^{59}$

El uso de la noción del currículo coincide con la difusión de nuevas creencias y preconcepciones sobre la efectividad de la escolarización, la cual, se pensaba, tenía que ser mirada como un todo estructurado y uniforme. Este nuevo énfasis acrecentó el control de los procesos de enseñanza-aprendizaje y resultó inseparable de los objetivos de la racionalidad moderna mencionada anteriormente. ${ }^{60}$ Las promesas de una ciencia de la técnica se han convertido en el principio sobre el cual se ha asentado, a lo largo de los últimos siglos, una diversidad de proyectos que buscan simplificar y hacer más eficiente la enseñanza. Según pp. 7-10.

${ }^{58}$ Max Horkheimer, Crítica de la razón instrumental, 1973, Buenos Aires, Editorial Sur,

${ }^{59}$ Stephen Kemmis, El curriculum: más allá de la teoría de la reproducción, 1998, Madrid, Morata, pp. 31-7.

${ }^{60}$ Cfr. David Hamilton, "Orígenes de los términos educativos 'clase' y curriculum", en Revista Iberoamericana de Educación, núm. 1, enero-abril, 1993, pp. 201-222 y La transformación de la educación en el tiempo. Estudio de la educación y la enseñanza formal, 1996, México, Trillas. 
esa perspectiva, la educción necesita la organización de secuencias y métodos que garanticen la estandarización de los alumnos. Para lograrlo, el educador y los alumnos tienen que estar sujetos a una regulación escrupulosa de los tiempos, disciplinas, contenidos y técnicas que son utilizadas para aprender. Esta generalización intelectual es posible y depende de que los contenidos se formalicen, se ciñan a un método y se evalúen. El resultado conseguido fue que la enseñanza y el aprendizaje quedaron más expuestos al escrutinio y el control exterior; como lo expreso Lewis Mumford:

Con el propósito de unificar todo el sistema, las limitaciones características de la Casa del Terror fueron introducidas, dentro de lo posible, en la escuela; el silencio, la ausencia de movimientos, la pasividad completa, la reacción sólo después de haber aplicado un estímulo externo, el aprender lecciones de memoria, la verborragia y la adquisición de conocimientos fragmentarios dieron a la escuela los felices atributos de la prisión y de la fábrica combinados. ${ }^{61}$

Para Nussbaum, la educación para el crecimiento económico requiere de un conjunto de competencias que no necesariamente se traducen en garantía para la igualdad de oportunidades y la disminución de la desigualdad. ${ }^{62}$ Por ejemplo, en la Unión Europea, se "definieron" las competencias básicas con la aprobación parlamentaria del documento Competencias clave. Textos aprobados por el parlamento europeo, el 26 de septiembre de 2006, ${ }^{63}$ y con la publicación de un segundo texto

${ }^{61}$ Lewis Mumford, Técnica y Civilización, 1945, Buenos Aires, Emecé, vol. I, p. 50.

${ }^{62} \mathrm{La}$ obra del investigador Carlos Muñoz Izquierdo, pionero de la investigación educativa en México, se ha dirigido a estudiar la relación entre desigualdad social y educación. Cfr., Carlos Muñoz Izquierdo, Origen y consecuencias de las desigualdades educativas: investigaciones realizadas en América Latina sobre el problema, 1996, México, FCE; La contribución de la educación al cambio social: reflexiones a partir de la investigación, 1994, México, Gernika; "El papel de la educación en el desarrollo económico y social; una perspectiva" en Revista de la Educación Superior, núm. 37, vol. 10, enero-marzo, 1981, pp. 18-43; "Educación y desarrollo económico y social. Políticas públicas en México y América Latina durante las últimas décadas del siglo XX”, en Perfiles Educativos, vol. XXIII, núm. 91, 2001, pp. 7-36.

${ }^{63}$ Cfr. Parlamento europeo, Competencias clave, 2006, Estrasburgo, texto aprobado por el parlamento europeo, Aprendizaje permante, en http://www.europarl.europa.eu/sides/getDoc. do?pubRef=-//EP//TEXT+TA+P6-TA-2006-0365+0+DOC+XML+V0//ES\#BKMD-11 [07 de junio de 2014]. 
de recomendaciones parlamentarias, el 18 de diciembre de $2006 .{ }^{64} \mathrm{El}$ Parlamento europeo estableció el proyecto asumiendo este enfoque con ocho categorías: a) competencias en lengua materna, b) comunicación en lenguas extranjeras, c) competencia matemática y competencia básica en ciencia y tecnología, d) competencia digital, e) aprender a aprender, f) competencias sociales y cívicas, g) sentido de la iniciativa y espíritu de empresa, $\mathrm{y}, \mathrm{h}$ ) conciencia y expresiones culturales. ${ }^{65}$

El análisis de estos documentos revela que este tipo de educación requiere de cierto conocimiento de la historia y la economía sin la necesidad de un enfoque crítico de las nociones de raza, género, clase o de los supuestos antropológicos y epistemológicos de sus teorías. Nussbaum describe esta situación del siguiente modo:

El pensamiento crítico no sería un componente importante de la educación para el crecimiento económico y, en efecto, no lo ha sido para los Estados que persiguen esa meta sin descanso [... L La libertad de pensamiento en el estudiante resulta peligrosa si lo que se pretende es obtener un grupo de trabajadores obedientes con capacitación técnica que lleven a la práctica los planes de las élites orientados a las inversiones extranjeras y el desarrollo tecnológico. ${ }^{66}$

El ejercicio crítico del pasado y el cuestionamiento ético resulta muy difícil a partir de este modelo educativo, debido al contenido de los materiales y a los métodos pedagógicos que fomentan. Se caracterizan por no estimular el cuestionamiento sino la asimilación, la reproducción de ideas para que el orden social se mantenga sin cambio. ${ }^{67}$ Sobre este tema en particular se ha reflexionado abundantemente; cuando la educación deja de ser crítica, la institución educativa se vuelve reproductora de sistema social, un espacio para la producción de un tipo

${ }^{64} \mathrm{Cfr}$. Parlamento europeo, Recomendaciones del parlamento europeo y del consejo sobre las competencias clave para el aprendizaje permanente, 2006, Estrasburgo, en http:// www.mcu.es/cine/docs/Novedades/Recomendacion_Parlamento_Europeo_Consejo_Aprendizaje_permanente.pdf [07 de junio de 2014].

${ }^{65} \mathrm{Cfr}$. Parlamento europeo, Competencias clave..., loc. cit.

${ }^{66}$ Nussbaum, Sin fines de lucro..., op. cit., p. 43.

${ }^{67}$ Cfr. Pierre Bourdieu, Capital cultural, escuela y espacio social, 2005, México, Siglo XXI, pp. 108-124; Henry Giroux, Teoría y resistencia en educación, 2004, México, Siglo XXI, pp. 117-29. 
particular de mercancía. El hombre como mercancía, como fuerza de trabajo calificado. La única finalidad está en "colocar" esta mercancía en el mercado de trabajo para venderla y que pueda ser consumida por el complejo sistema de producción social. ${ }^{6}$ En algunos de esos modelos que se ocupan de manera exclusiva de la renta, se acostumbra el dogmatismo histórico, haciendo caso omiso de las desigualdades y de la responsabilidad social de los especialistas. ${ }^{69}$

Según Nussbaum, a los estudiantes se les enseña que lo relevante es el bienestar individual o del ciudadano promedio, no el de los menos favorecidos en una sociedad, y se estimula a ubicarse como integrantes de una clase privilegiada que se encuentra en situación de progreso en relación con el resto de la población. ${ }^{70}$ Se carece de una reflexión sensible sobre los problemas sociales y las desigualdades redistributivas $\mathrm{y}$, aunque los contrastes sociales pueden ser escandalosos, no generan la más mínima respuesta de los estudiantes mientras crezca la economía. Su respuesta es exclusivamente técnica y carece, en muchos casos, de responsabilidad ética y social. Nussbaum considera que, cuando la pobreza deja de ser una cifra y adquiere rostro, las preocupaciones exclusivas por crecimiento generan discusiones. Se desvela que determinadas políticas públicas, aunque prometen un bienestar económico futuro, implican la precariedad e incluso el hambre para una parte de la población. Eso explica, en parte, el desinterés que generan las humanidades para los promotores de este modelo educativo:

Los especialistas en educación para el crecimiento económico no se limitan a hacer caso omiso de las disciplinas artísticas y humanísticas. En realidad, les tienen miedo, pues el cultivo y el desarrollo de la comprensión resultan especialmente peligrosos frente a la moral obtusa que a su vez es necesaria para poner en práctica los planes de crecimiento económico

${ }^{68}$ Cfr. De la Isla, Reflexiones en plural..., op. cit., p. 5.

${ }^{69}$ Sobre la importancia de la crítica en la enseñanza de la historia, $v$. Reynaldo Sordo, "Historia de los cursos de México" en Estudios. Filosofia. Historia. Letras, núm. 97, Verano 2011, pp. 63-9. op. cit.

${ }^{70}$ Cfr. Nussbaum, Sin fines de lucro..., op. cit., p. 44; de la Isla, Reflexiones en plural..., 
que ignoran la desigualdad. Resulta más fácil tratar a las personas como objetos aptos para ser manipulados si uno nunca aprendió a verlas de otra manera. ${ }^{71}$

En otras palabras, la educación para el crecimiento económico ofusca la conciencia moral y necesita la "producción" de personas que prefieran las abstracciones y no aprendan a reconocer lo humano; que hablen una jerga de grupo, se comporten con docilidad frente a los más privilegiados y pidan esa misma docilidad al resto del mundo. La lectura rigurosa, el diálogo y las manifestaciones artísticas son enemigos de este carácter obtuso; le piden a la imaginación que se extienda más allá de las fronteras habituales; imposibilitan que emerja la persona con sus propias ideas, cuestione el orden tradicional y, sobre todo, que no se conforme con las cosas tal y como las ha encontrado. ${ }^{72}$ En palabras de Carlos de la Isla:

Ciertamente, en este sistema de funciones, opuesto a creaciones, el más aplaudido, el más solicitado, el ideal es el 'hombre bien redondeado', porque su redondez propicia la rotación perfecta técnicamente definida. Las aristas propias, la imaginación atrevida, las decisiones originales, el riesgo, el sello de autonomía, la invención asombrosa, en una palabra, la personalidad, no tiene cabida en esta estructura herméticamente armada sobre el diseño estricto de la productividad. ${ }^{73}$

Si bien no existen modelos puros de educación para el crecimiento económico, sí puede detectarse un acercamiento de los sistemas educativos de todo al mundo a este modelo, que lesiona los derechos fundamentales y los compromisos constitucionales de casi todas las naciones democráticas. Tal aproximación se ha realizado de manera irreflexiva porque no ha tomado en cuenta los peligros que entraña para las democracias, el desarrollo de las capacidades y la dignidad humana del que debe gozar

${ }^{71}$ Nussbaum, Sin fines de lucro..., op. cit., p. 46.

${ }^{72}$ Cfr. Georges Gusdorf, ¿Para qué los profesores?, 1969, Madrid, Cuadernos para el Diálogo, p. 18; Carlos de la Isla, De esclavitudes y libertades. Ensayos de Ética, Educación y Política, 2006, México, Porrúa-ITAM; "Ética y Universidad", en Estudios. Filosofía. Historia. Letras, núm. 69, Verano 2004, pp. 7-18.

${ }^{73}$ González Díaz, Entrevista a Carlos de la Isla..., op. cit., pp. 111-34. 
toda persona. ${ }^{74}$ En sentido contrario, el modelo del desarrollo humano está comprometido con una democracia humana, sensible y dedicada a promover las oportunidades de cada uno de sus habitantes.

Según Martha Nussbaum, se deberán inculcar algunas aptitudes en todos los ciudadanos: a) la reflexión sobre las cuestiones políticas, que exigen una rigurosa argumentación y debatirlas sin complacencias hacia la autoridad o la tradición; b) la aptitud para reconocer a los otros ciudadanos como personas con la misma dignidad y derechos, independientemente de cualquier diferencia racial, religiosa, género u orientación sexual y contemplarlos con respeto, como fines en sí mismos y no como medios; c) la aptitud para interesarse por la vida de los otros, de entender las consecuencias que cada política implica para las oportunidades de los demás ciudadanos e incluso de personas que viven en otras naciones; d) la aptitud para imaginar cuestiones complejas que afectan la vida humana y su desarrollo, y de reflexionar sobre las etapas de la vida y las relaciones familiares, la enfermedad y la muerte, en sus dimensiones concretas; e) la aptitud para emitir juicios críticos realistas y fundamentados sobre los actores políticos; f) la aptitud para pensar en el bien común de la nación; $y, g$ ) la aptitud para concebir a la propia nación como parte del mundo.

Si bien no hay nada que objetar a la buena calidad educativa en materia de ciencia y tecnología, ni se puede afirmar que los países deban dejar de mejorar esos campos, me preocupa que otras capacidades igualmente fundamentales corran el riesgo de perderse en el trajín de la competitividad, pues se trata de capacidades vitales para la salud de cualquier democracia y para la creación de una cultura internacional digna que pueda afrontar de manera constructiva los problemas más acuciantes del mundo. ${ }^{75}$

Nussbaum aclara que no pretende afirmar "que las ciencias exactas y las otras ciencias sociales, como la economía, no sean esenciales también para la educación de los ciudadanos, pero nadie está proponiendo que esas disciplinas queden atrás"; 76 incluso es posible constatar que la edu-

${ }^{74}$ Martha Nussbaum, "Capabilities and Human Rights" en Fordham Law Review, vol. 66, 1997, pp. 273-300.

${ }^{75}$ Nussbaum, Sin fines de lucro..., op. cit., p. 25.

${ }^{76}$ Ibid., p. 26. 
cación científica busca el desarrollo, las facultades de la crítica, el análisis lógico y la imaginación. "La ciencia, si se le práctica de manera adecuada, no es enemiga sino más bien amiga de las humanidades". ${ }^{77}$ Además, la educación no puede preparar sólo para la ciudadanía, sino también para darle sentido a la vida y respetar otras identidades.

La educación debe promover la facultad de imaginar la experiencia del otro, que debe formarse, si se quiere vivir en sociedades pluralistas. Finalmente, demostrará que el interés económico también se nutre de las artes y humanidades, para favorecer un ambiente de innovación, responsable de los recursos. Así, no existiría verdaderamente el dilema entre la educación para la renta y la educación para la ciudadanía, puesto que la prosperidad económica requiere aptitudes necesarias para ser un buen ciudadano.

\section{Educación y vulnerabilidad humana}

Un aspecto que ocupa un lugar central en la reflexión educativa de Martha Nussbaum es el que está relacionado tanto con aprender a convivir como con la educación en los derechos humanos. En muchas ocasiones se fomenta la idea de que la identidad nacional y que la propia tradición es infalible y se considera cualquier diferencia como deficitaria. Nussbaum señala: "el choque de civilizaciones constituye un elemento interno de todas ellas: siempre existen algunas personas que están dispuestas a vivir con las demás en condiciones de respeto mutuo y reciprocidad, y otras que se conforman con la dominación". ${ }^{78}$ Eso hace indispensable la comprensión de las condiciones de posibilidad para formar personas dispuestas a convivir respetuosamente con los demás y evitar la intolerancia. La pregunta es cómo se adquiere la capacidad del respeto en las sociedades democráticas, qué provoca que los seres humanos aspiren a la dominación.

En el pensamiento de Nussbaum, un aspecto fundamental es analizar las fuerzas internas que dentro de cada persona se oponen al respeto mutuo y a la reciprocidad. Esto no quiere decir que las estructuras

${ }^{77}$ Ibid., p. 27.

${ }^{78}$ Ibid., p. 53. 
políticas y sociales no ejerzan una gran influencia en el comportamiento de los individuos, pero resulta más importante una explicación de lo que ocurre en cada individuo. El elemento clave se relaciona con la experiencia de vulnerabilidad de todas las personas y las herramientas que se ofrecen al individuo para enfrentar el fracaso:

La vulnerabilidad es, sin duda, una de las cuestiones centrales de mi obra. En ella se vinculan dos grandes temas de mi trabajo: las emociones y la filosofía política. Ahora mismo estoy trabajando en las emociones que debería tener una sociedad decente, en la necesidad de una educación de las emociones. Las emociones que analizo implican el reconocimiento de nuestra vulnerabilidad ante elementos externos que no controlamos. Siempre que trabajo en filosofía política me pregunto cómo es posible que la sociedad enfrente la vulnerabilidad humana, cómo es posible hacer desaparecer algunas formas de vulnerabilidad, dar más seguridad, haciendo disponibles para las personas las formas buenas de vulnerabilidad a través del amor, la amistad y otras. ${ }^{79}$

La educación necesita vencer la resistencia a reconocer la propia finitud y tener en cuenta que es un elemento central en el desarrollo de las actitudes de tolerancia. ${ }^{80}$ Según Nussbaum, las experiencias infantiles nos permiten encontrar el espacio en el que determinadas normas e instituciones sociales inhiben y desarrollan determinadas actitudes y comportamientos. Desafortunadamente, las propuestas para la educación ignoran la psicología del desarrollo humano; las investigaciones revelan que la primera experiencia infantil es la de llegar a un mundo que no se controla y en el que el pequeño se encuentra completamente indefenso, vulnerable. Angustia y satisfacción se suceden, momentos en el que el "mundo entero" parece girar en torno a la satisfacción de sus necesidades y momentos en los que la conciencia de la propia indigencia es muy aguda y la necesidad no se puede satisfacerse oportunamente: "El ser humano presenta un nivel de indefensión física des-

${ }^{79}$ Martha Nussbaum, Libertad de conciencia: el ataque a la igualdad de respeto. Vivir en democracia implica respetar el derecho de las personas a elegir estilos de vida con los que no estoy de acuerdo. (entrevista de Daniel Gamper Sachse), 2010, Bs. As., Katz, pp. 88-9.

${ }^{80}$ Cfr. Nussbaum, Paisajes del pensamiento..., op. cit., p. 94-7. 
conocido en el reino animal, que se combina con un grado muy superior de complejidad congnitiva". ${ }^{81}$ Lo anterior hace indispensable una reflexión sobre el extraño correlato entre indefensión y el deseo de ser cada día más capaces, la problemática relación que todo hombre tiene con la impotencia, la muerte, la finitud y el deseo imperioso de trascender todas las condiciones que nos parecen inaceptables.

Desde la infancia, la persona va cobrando conciencia de lo que sucede a su alrededor, de que no puede hacer nada para cambiarlo y que necesita de la atención continua de los demás. Esta experiencia de la vulnerabilidad se une, en muchas ocasiones, a la ansiedad y a la sensación de vergüenza que siente la persona al percatarse de que no se es omnipotente sino, constitutivamente limitada. "De esa ansiedad y esa vergüenza deriva entonces un deseo urgente de plenitud que nunca se pierde del todo, por más que el niño aprenda que es apenas una parte de un mundo compuesto de seres finitos e incompletos". ${ }^{82}$ Esta situación requiere de una sólida formación moral, porque, al menos para el infante, las otras personas son instrumentos que lo satisfacen y no desprecia la oportunidad de controlarlas, porque lo proveen de lo que necesita. Lo comprendió Rousseau y lo expresó en su obra Emilio o de la Educación. ${ }^{83}$ La propia debilidad del menor podía propiciar la deformación del carácter y, posteriormente, la aparición de conductas crueles e incluso inmorales, salvo que ese narcicismo infantil y la tendencia angustiosa a la dominación encontraran una manera más saludable de manejarse.

A esta vergüenza primitiva se le une otro sentimiento muy poderoso: el de la repugnancia por los desechos del cuerpo. "Como la mayoría de las emociones, la repugnancia representa un fundamento evolutivo innato, pero también supone cierto aprendizaje, pues no aparece en el niño hasta el momento en que se le enseña a ir al baño, cuando sus capacidades cognitivas han madurado lo suficiente. Por tanto, la sociedad ejerce un alto nivel de influencia en la dirección que adopta esa repugnancia". 84

${ }^{81}$ Nussbaum, Sin fines de lucro..., op. cit., p. 55.

${ }^{82}$ Ibid., p. 56.

${ }^{83}$ Jean Jacques Rousseau, Textos completos, 2011, Buenos Aires, Tecnibook, pp. 31-2.

${ }^{84}$ Nussbaum, Sin fines de lucro..., op. cit., p. 57. 
En su argumentación, Nussbaum remite a las más recientes investigaciones que muestran que la repugnancia implica un componente cognitivo relacionado con las nociones de contaminación y de impureza. En otras palabras, la repugnancia representa un rechazo a la contaminación que producen determinados objetos - excrecencias, heces, cadáveres-que constatan nuestra propia condición animal y mortal. Al distanciarse de esos "desechos" se transfiere la angustia que genera "tener" o "ser" animales y mortales; ${ }^{85}$ en otros términos, la repugnancia es la negación de nuestra propia humanidad. Esto no quiere decir que la repugnancia no sea valiosa para evitar el peligro:

Sin embargo, cuando la repugnancia se vincula con el narcisismo básico del niño, pronto comienza a causar un daño concreto. Para tomar distancia de la propia animalidad resulta eficaz proyectar los rasgos de esa animalidad (como el mal olor, la viscosidad y la suciedad) sobre algún grupo de personas; luego, se trata a esas personas como agentes de contaminación o impureza transformándolas en una clase inferior y, más concretamente, en una frontera o "zona intermedia" entre la persona que siente repugnancia y los rasgos tan temidos y estigmatizados de la animalidad. ${ }^{86}$

Posteriormente, el infante aprende de la sociedad adulta que existen grupos sociales sobre los que puede recaer esta repugnancia, por ejemplo, sobre los pobres, los homosexuales, los afroamericanos o cualquier grupo considerado inferior. ${ }^{87}$ "En efecto, esos grupos funcionan como el otro animal, mediante cuya exclusión un grupo privilegiado se define como superior o, incluso, trascendente. Una de las manifestaciones típicas de esta clase de repugnancia consiste en evitar el contacto físico con las personas pertenecientes al grupo subordinado y hasta con los objetos que éstas hayan tocado". ${ }^{88}$

De este modo, en el individuo narcisista la angustia generada por la propia vulnerabilidad encuentra satisfacción en el dominio de los demás y la creación de jerarquías sociales que garanticen la erradi-

${ }^{85} \mathrm{Cfr}$. Martha Nussbaum, El ocultamiento de lo humano, repugnancia, vergüenza y ley, 2006, Bs. As., Katz, pp. 90-4; 116-20.

${ }^{86}$ Nussbaum, Sin fines de lucro..., op. cit., p. 58.

${ }^{87}$ Cfr. Ryszard Kapuściński, Encuentro con el otro, 2008, Barcelona, Anagrama.

${ }^{88}$ Nussbaum, Sin fines de lucro..., op. cit., p. 59. 
cación, al menos psicológica, de su propia finitud. La intensidad del rechazo dependerá, en primer lugar, de las normas familiares y sociales; una manera de mejorar las actitudes sociales, según Nussbaum, implica resolver o moderar ese sentimiento de ansiedad generado por nuestra propia naturaleza débil y vulnerable. Una forma de hacerlo, previamente recomendada por Rousseau, supone crear las condiciones para que las personas resuelvan por sí mismas y con el mayor grado de autonomía su actividad cotidiana. Las normas sociales deben permitir "afrontar ese dolor de manera creativa, comunicando a los niños el mensaje de que todos los seres humanos somos vulnerables y mortales, pero no por eso debemos odiar ni rechazar ese aspecto de la vida humana, sino que podemos abordarlo mediante la reciprocidad y la ayuda mutua". ${ }^{89}$

El reconocimiento de esa debilidad nos permite transformarnos en seres sociales y construir una comunidad humana. La propia limitación y finitud puede ser el punto de partida para construir una comunidad interdependiente y respetuosa; sin embargo, para Nussbaum existen sociedades que enseñan el deseo de ser invulnerables y de reinar sobre los demás. Mediante un conjunto de normas familiares y sociales, se transmite continuamente el mensaje de que la perfección y el control sobre los demás son el fundamento del éxito en la vida profesional. En algunas ocasiones, estos mensajes se transmiten de manera no consciente, como creencias que prometen la prosperidad a cambio de tener la capacidad de controlar cualquier eventualidad; en este proceso, la escuela juega un papel fundamental: es una fuerza crítica frente al "nosotros" puro y sin falla alguna y el "ello", lleno de elementos contaminantes y dignos de repugnancia. Permite una mirada a la complejidad de la experiencia humana, que evita la dicotomía y favorece la comprensión de las otras personas como fines y no como medios, como Nussbaum asevera: "esta capacidad de sentir interés y de responder con empatía e imaginación constituye un elemento básico de nuestra herencia evolutiva". ${ }^{90}$ En muchas ocasiones, darle

${ }^{89}$ Ibid., p. 60.

${ }^{90}$ Ibid., p. 63. 
rostro concreto a las personas, percibir su sufrimiento y hacer el esfuerzo de ponerse en su lugar posibilita una respuesta más considerada y respetuosa hacia el otro. No cabe duda de que empatía no equivale a moral, pero puede brindar elementos esenciales; según Nussbaum, "a medida que se va formando la capacidad de interés por el otro, aumenta el deseo de controlar la propia agresividad. El niño reconoce que los otros seres no son sus esclavos, sino que son personas separadas con derecho a vivir su vida". ${ }^{91}$

En ese mismo sentido transitan las filosofías del reconocimiento, para las que el yo es el resultado de un nosotros original..$^{22}$ Empero, la comprensión y la empatía, por sí mismas, no pueden considerarse como el único criterio que permite el trato "decente" en la vida social. Es perfectamente compatible ser comprensivo con los miembros del propio grupo y no serlo con alguien ajeno: "también se puede contener el sentimiento de comprensión por motivos erróneos, como por ejemplo cuando responsabilizamos a la víctima por su desgracia. En los Estados Unidos muchas personas creen que los pobres son los culpables de su propia pobreza por haraganería y falta de esfuerzo. Por tanto, aunque gran parte de las veces se equivocan, no sienten comprensión por esos sectores" ${ }^{93}$ Como se ha dicho, cultivar la comprensión no basta para que una persona aprenda a convivir: al contrario, puede ponerse al servicio de las élites intolerantes.

La cultura debería ofrecer a las personas la posibilidad de mirar sin angustia su propia limitación, inhibir los efectos indeseables del narcisismo y aceptar con pudor la propia finitud para construir una sociedad interdependiente y solidaria. Desafortunadamente, los modelos culturales y educativos insisten, todavía y de manera casi exclusiva, en la necesidad de convertirse en una persona absolutamente independiente, que tenga todo bajo su control, hasta que en el intento llegue

${ }^{91}$ Ibid., p. 64.

${ }^{92}$ Por ejemplo las referencias de Axel Honneth sobre Martha Nussbaum en relación al concepto de "reificación" para designar formas extremas de utilización instrumental de otras personas o de los esfuerzos de una etiología social de la reificación. $V$. Axel Honneth, Reificación. Un estudio en la teoría del reconocimiento, 2007, Buenos Aires, Katz, pp. 16; 31; 130.

${ }^{93}$ Nussbaum, Sin fines de lucro..., op. cit., p. 65. 
a corroerse a sí mismo. ${ }^{94}$ Esto es paradójico, justo cuando el individuo se desenvuelve en un mundo que no controla realmente:

La vida misma se ocupa de desenmascarar esa ficción casi todos los días, cada vez que el futuro "hombre de verdad" siente hambre, cansancio, ansiedad, malestar físico o temor. Así, en la psique de la persona que vive este mito se genera una oleada de vergüenza: se supone que debo ser un "hombre de verdad", pero siento que no controlo mi entorno, ni siquiera mi propio cuerpo. Si bien la vergüenza es una respuesta casi universal ante la impotencia humana, se torna mucho más intensa en las personas criadas bajo el mito del control absoluto, en lugar del ideal de la interdependencia y la ayuda mutua". ${ }^{95}$

La educación debe tener entre sus objetivos que las personas no aspiren sólo al control ni a la invulnerabilidad, sino que aprender a reconocer la experiencia de la debilidad humana en las distintas circunstancias sociales y cómo las decisiones políticas pueden afectarla. El deseo narcisista se debe combatir, por un lado, con el fomento de la sana autonomía y, por otro, al ofrecer la oportunidad de identificarse con los demás: "ver el mundo a través de los ojos ajenos y a sentir mediante la imaginación el sufrimiento de las otras personas. Sólo de ese modo será posible que éstas, a la distancia, le parezcan reales e iguales a él". ${ }^{96}$

Un último aspecto sobre el que merece la pena reflexionar es el referido a las conductas de obediencia y servilismo que manifiestan las personas frente a las disposiciones o normas recibidas del líder o de los pares del grupo al que pertenecen. Estas conductas parecen acrecentarse por la sensación de invulnerabilidad que les proporciona la solidaridad con sus iguales. Por eso, no es extraño que la persecución de un grupo ajeno se origine de la "solidaridad" con el propio grupo. Al respecto, la educación juega un papel fundamental, como reflexión y crítica de las prácticas culturales que contradicen a la conciencia o que justifican la intolerancia y la exclusión: "la sumisión o el servilismo ante la autoridad caracterizan muchas veces la vida grupal, y la confianza

${ }^{94}$ Byung-chul Han, La sociedad del cansancio, 2012, Madrid, Herder.

${ }^{95}$ Nussbaum, Sin fines de lucro..., op. cit., p. 67.

${ }^{96}$ Ibid., p. 68. 
de un líder que se supone invulnerable es uno de los modos en que el ego frágil se protege de la inseguridad". ${ }^{97}$

Incluso personas que en ciertas condiciones pueden tener una conducta respetuosa y considerada, cuando las estructuras sociales lo permiten, son capaces de humillar y estigmatizar a los demás, especialmente cuando se les hace creer que son superiores. En otras palabras, las actitudes intolerantes e inclusive crueles no derivan sólo de una crianza limitada o de una sociedad en crisis moral, sino de algunas disposiciones que promueven o afectan el proceder de personas que se consideran decentes. ${ }^{98}$ "No obstante, la situación también importa, pues la conducta de una persona imperfecta sin duda será mucho peor si se la ubica en determinadas estructuras"; 99 en general, los ambientes en los que los individuos no se sienten personalmente responsables de sus actos son más proclives de desarrollar conductas inapropiadas e intolerantes. Es común que los individuos se comporten de manera desconsiderada bajo la protección del anonimato, cuando nadie manifiesta una opinión crítica o cuando se justifique algún acto, deshumanizando al grupo que recibe las acciones.

La historia demuestra que resulta fácil conducirse de manera desconsiderada si el "otro" que se tiene frente a sí es representado como alguien que no tiene nombre, como un animal o como "algo" carente de dignidad, es decir, cuando el otro es objetivizado e instrumentalizado en aras de valores abstractos más importantes, como el orden social o la justicia. La educación puede ayudar a las personas a descubrir tanto que los demás miembros de una sociedad merecen y tienen dignidad, como su propio sentido de responsabilidad individual.

\section{Consideraciones finales}

El problema de las humanidades que Martha Nussbaum busca comprender no consiste en el cierre de programas y cursos sobre humanidades,

${ }^{97}$ Ibid., p. 69.

${ }^{98}$ Theodor Adorno, Ensayos sobre la propaganda fascista: psicoanálisis del antisemitismo, 2005, Barcelona, Paradiso; Kurt Lewin, Resolving social conflicts: and field theory in social science, 1997, Washington, American Psychological Association.

${ }^{99}$ Nussbaum, Sin fines de lucro..., op. cit., p. 71. 
ni siquiera en los procesos de mercantilización que describe en sus libros -asuntos que no son originales y que esta investigación intenta mostrar-, sino en la necesidad de repensar verdaderamente lo que es propio del hombre en el siglo XXI. La crisis de la educación no comenzó con la crisis económica de 1998: es una manifestación del malestar de un conflicto que ha ocurrido por décadas y que en realidad se relaciona con la crisis que de las humanidades; el conflicto de las humanidades es, en realidad, la crisis de la época. A la luz de lo que hemos dicho, las reflexiones de Nussbaum en El cultivo de la humanidad y en Sin fines de lucro son descripciones y críticas que proporcionan un acercamiento filosófico al problema de las humanidades y de la educación en el siglo XXI.

Un aspecto fundamental en la obra de Nussbaum tiene que ver con la capacidad que tiene la Universidad para comprender y aceptar la propia vulnerabilidad y el fracaso. Las dificultades para comprender las diferencias en una sociedad pluralista se deben a la dinámica perniciosa entre vergüenza y repugnancia, respuestas espontáneas ante la impotencia humana. Según la filósofa, las sociedades y los sistemas educativos que inculcan el "mito del control absoluto" dificultan la cooperación y la comprensión mutua y generan un aumento de la ansiedad y de conductas intolerantes. Siguiendo las reflexiones de Rousseau, insiste en que los estudiantes deben aprender a identificarse con las dificultades de la condición humana: desarrollarse en la autonomía y en la aceptación de sí mismo; sólo de ese modo pueden mirar a los demás como personas en su realidad concreta. La comprensión de la interdependencia es un eje de la democracia que la educación en humanidades puede fortalecer, porque una democracia que esté repleta de ciudadanos sin empatía e indiferentes generará marginalización y violencia.

Su planteamiento tiene el mérito de proponer la finitud y la vulnerabilidad como puntos de partida para repensar lo humano y la educación; no obstante, su visión es reduccionista porque se sustenta en la "existencia" de un fenómeno natural y pretendidamente universal. Invoca expresiones como narcicismo, vergüenza, repugnancia y poder, como si tales sentimientos o realidades pudieran existir independientemente de la cultura, como si la esencia "natural" del hombre se redujera a la 
biología y los sentimientos y careciera de importancia la dilucidación epistemológica de las nociones que propone. El uso de los conceptos es el mismo del sentido común y no tienen otro examen que las investigaciones empíricas que le sirven de sustento. Lo mismo ocurre con las ideas de multiculturalismo, repugnancia y tolerancia.

Parece que las "nuevas humanidades", como las llama Derrida, requieren repensar lo que es propio del hombre y explorar nuevas herramientas conceptuales para nombrarlo. La propuesta de Martha Nussbaum no es estéril en su diagnóstico, pero quizá lo es en relación a la explicación y la validez de una determinada propuesta de solución. La mayoría estará de acuerdo con Nussbaum en cuanto a la vigencia de los conceptos "otredad", "diálogo", "pluralismo cultural”, "liberalismo", "derechos humanos", pero sin una reflexión que los clarifique y los integre son de poca utilidad.

Si se acepta que la "finitud" y la "vulnerabilidad" son experiencias existenciales del hombre, se hace indispensable comprenderlas más ampliamente y ligarlas con el fenómeno de la consciencia de sí mismo y con la noción de creaturalidad. Peter Berger lo dice de este modo: "El hombre, tal como lo conocemos empíricamente, no puede ser concebido fuera de su continuo vuelco hacia el mundo en el cual se encuentra $[\ldots]$ porque justo el mundo natural le resultó insuficiente al hombre y construyó ese segundo mundo de la cultura. En ella el hombre se hace a sí mismo y puede expresar sus necesidades. Es ella el espacio en el que cada uno se desenvuelve como participes de una comunidad humana". ${ }^{100}$

La expresión "humanidades" incluye un núcleo duro de contenidos que no se podrían confundir con otras disciplinas de las ciencias experimentales o las ciencias sociales. La expresión refiere a un determinado contenido y a una serie de áreas relacionadas con la cultura humana, tales como la filosofía, la literatura, la filología, la historia, la antropología, el arte, el estudio de las religiones y otras relacionadas. Esta expresión no hace referencia exclusivamente al cuerpo de contenidos, sino a los métodos de enseñanza y sobre todo a la finalidad de los mismos. Las humani-

${ }^{100}$ Peter Berger, El dosel sagrado. Para una teoría sociológica de la religión, 1969, Buenos Aires, Amorrortu, p. 15. 
dades no se pueden concebir como el estudio minucioso y libresco, sino que deben ser, siguiendo la expresión de Mortimer Adler, una gran conversación con otros hombres. La importancia de la conversación es indiscutible como ruta para el mutuo reconocimiento. Las humanidades, en ese sentido, no enseñan sólo un canon, sino que lo interrogan, imaginan posibilidades y le permiten al hombre la capacidad de autodistanciarse de sí mismo, pensar alternativas y, por ende, saber que se cuenta con opciones y con la capacidad de elegir.

Las humanidades representan y constituyen el pensamiento crítico indispensable para el actuar independiente y para el desarrollo de una inteligencia resistente a todo tipo de dogmatismo y a cualquier tradición ciega. Otro de los beneficios que ofrece la educación en humanidades es que las personas que las cultivan aprenden a imaginar situaciones en la que se encuentran otros seres humanos.

¿Acaso podría concebirse mundo humano que careciera completamente de las humanidades? La única respuesta posible es no: no sería posible concebir un mundo auténticamente humano sin el espacio en el que el hombre se puede realizar. Imaginar un mundo en el que no hubiera espacio para lo humano sería una nueva forma de barbarie.

\section{Epílogo}

Una vez más, nos referimos al final del primer acto de El oro de Rin de Wagner. La figura del nibelungo, Alberich, se enfrenta al dilema que nos plantea nuestra propia humanidad: aceptar la finitud y la interdependencia o negarla de manera narcisista y concentrarse en el dominio de los demás. El nibelungo negó su humanidad y por ende la humanidad de los demás. Efusivo gritó: “¡Yo renuncio al amor!” El otro camino sería el reconocimiento de sus límites y abrirse al otro: “¡Renuncio al poder y elijo el amor!" 